九州大学学術情報リポジトリ

Kyushu University Institutional Repository

\title{
Trial Construction of Molecular Linkage Map of Japonica Rice
}

Kubo, Takahiko

Plant Breeding Laboratory, Faculty of Agriculture, Kyushu University

Yoshimura, Atsushi

Plant Breeding Laboratory, Faculty of Agriculture, Kyushu University

Iwata, Nobuo

Plant Breeding Laboratory, Faculty of Agriculture, Kyushu University

https://doi.org/10.5109/24255

出版情報 : 九州大学大学院農学研究院紀要. 43 (1/2)，pp.95-101，1998-11. Kyushu University バージョン：

権利関係: 
J. Fac. Agr., Kyushu Lniv., 43 (1·2), 95-101 (1998)

\title{
Trial Construction of Molecular Linkage Map of Japonica Rice
}

\author{
Takahiko Kubo, Atsushi Yoshimura and Nobuo Iwata
}

\author{
Plant Breeding Laboratory, Faculty of Agriculture, \\ Kyushu University, Fukuoka 812-8581, Japan \\ (Received July 31,1998 and accepted August 7, 1998)
}

\begin{abstract}
A genetic linkage may for Japonica rice has been constructed from 58 random amplified polymorphic DNA (RAPD) and nine restriction fragment length polymorphism (RFLP) markers.

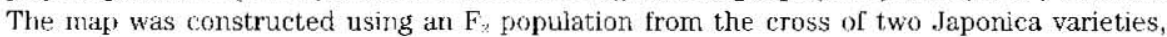
Taichung 65 and Nipponbare. The RAPD linkage groups were assigned to the ten rice chromosomes on the existing RFLP map by RFLP analysis. This map should form the basis for the analysis of useful genes in Japonica rice.
\end{abstract}

\section{INTRODUCTION}

Rice is the staple food in Japan and a great deal of efforts has been devoted to rice breeding for years. The cultivated rice, Oryza sativa L., is composed of three ecotypes; Japonica, Javanica and Indica. Japanese cultivated rice varieties belong to the Japonica type which have extremely limited genctic variabilities.

In early genetic linkage analysis in rice, morphological markers were used in the construction of classical genetic maps which included even the undesirable characters. More recently, advances in molecular technologies has paved the way for the construction of a high-density molecular map in rice (McCouch et al., 1988; Kurata et al., 1994; Causse et al., 1994). These rice linkage maps have facilitated various genetic analyses, i.e., localization of quantitative trait loci (QTLs), tagging and cloning of insect and disease resistance genes and physical mapping. All these maps, however, were based on Indica/Japonica (or Javanica) crosses and interspecific crosses. Japonica/Japonica cross has not been used for map construction because of limited polymorphisms. But considering its usefulness to the breeding of Japanese rice varieties, it may be desirable to accumulate as many DNA markers obtained from Japonjca varieties as possible and construct a Japonica linkage map based on these markers.

Recently, a new genetic assay based on polymerase chain reaction (PCR) amplification, random amplified polymorphic DNA (RAPD), have been developed. RAPD analysis is much faster and requires less DNA than RFLP analysis. Moreover, they are capable of detecting more polymorphisms than RFLP analysis (Welsh and McClelland, 1990; Williams et $a l ., 1990)$. Because of these advantages, RAPD provided a possibility for mapping closely-related plants and animals, and demonstrated to be useful in linkage analysis, phylogeny and cultivar identification.

In this paper the molecular linkage map of Japonica rice obtained by means of RAPD and RFLP markers is presented. We envisioned to develop a fully saturated Japonica rice linkage map for use in breeding and genetics. 


\section{MATERIALS AND METHODS}

\section{Plant materials and DNA extraction}

An $\mathrm{F}_{2}$ population of 80 plants developed from a cross between two Japonica varieties, Taichung 65 and Nipponbare, were used for mapping. The parents and their progenies were grown at the experimental farm of Kyushu University. DNA from leaves of these materials was extracted by CTAB (Cetyltrimethyl ammonium bromide) method (Rogers and Bendich, 1988).

\section{PCR reaction}

Eight hundred 10-base arbitrary primers were used for RAPD analysis (Primer kits $A$ to AN; Operon Technologies). The PCR reactions were performed based on the protocols of Williams et al. (1990). The reaction volume was $25 \mu \mathrm{l}$ and contained $10 \times$ buffer (containing $100 \mathrm{mM}$ Tris-HCl $\mathrm{pH} 9.0,500 \mathrm{mM} \mathrm{MgCl}, 1 \%$ Triton $\mathrm{X}-100$ ), $100 \mu \mathrm{M}$ of each dNTP type, $0.4 \mu \mathrm{M}$ of primer, 1.0 unit of Taq DNA polymerase (Promega) and $20 \mathrm{ng}$ of genomic DNA. DNA amplification was performed in a Thermal sequencer TSR-300 (IWAKI) with 40 cycles of 1 min at $94^{\circ} \mathrm{C}, 1$ min at $36^{\circ} \mathrm{C}, 2$ min at $72^{\circ} \mathrm{C}$, and finally incubated for $7 \mathrm{~min}$ at $72^{\circ} \mathrm{C}$. Amplification products were separated by electrophoresis through $1.5 \%$ agarose gels in $0.5 \times \mathrm{TAE}$ buffer. DNA fragments were visualized by UV light after staining with ethidium bromide.

The designation of RAPD markers included both the primer name and the estimated size of the product in base pair.

\section{RFLP analysis}

Two hundred eight RFLP markers mapped by Saito et $a l$. (1991) (designtated as $X N p b$ numbers) and by Kurata et al. (1994) (designated as $C, R$ numbers) were used. DNA was digested with fourteen restriction enzymes (ApaI, Bam HI, BglII, DraI, EcoRI, EcoRV, HaeIII, HindIII, HinfI, KpnI, MstI, PstI, SalI, XbaI), subjected to electrophoresis in $1.0 \%$ agarose gels, and blotted onto a positively charged Nylon membrane (Boehringer Mannheim). Hybridization and detection were carried out with the ECL direct nucleic acid labeling and detection system (Amersham International plc); according to the manufacturer's instructions.

\section{Data analysis and map construction}

Goodness of fit to $3: 1$ or 1:2:1 segregation ratios in $F_{2}$ population was determined by chi-square test. Recombination values were estimated by the maximum likelihood equation (Allard, 1956), and were converted into genetic map distances (cM) using the Kosambi function. Loci were considered independent when the chi-square probability level was $>0.05$. The chromosomal assignment of each linkage group was established by RFLPs, and RAPD markers located onto the RFLP map developed from a Japonica/Indica cross (Asominori/R24) by Tsunematsu et al. (1996). 


\section{RESULTS AND DISCUSSION}

\section{RAPD analysis}

Eight hundred RAPD primers were tested for the initial survey of polymorphisms between Taichung 65 and Nipponbarc. Seven hundred three primers produced scorable amplification fragments and fifty-nine amplified a total of 69 polymorphic DNA fragments. Of these, 64 polymorphic bands showed segregation in the $\mathrm{F}_{2}$ population in Mendelian ratios (Fig. 1). The other five polymorphic bands either segregated in a non-Mendelian fashion or were not reproducible. Two markers of the 64 RAPDs (2.6\%) showed distorted

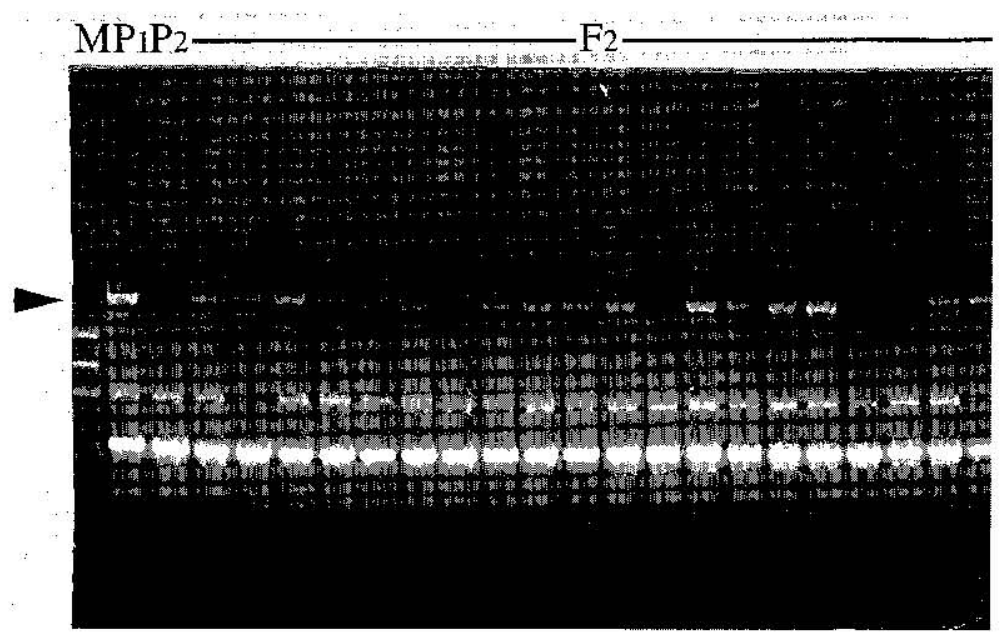

Fig. 1 Segregation of RAPD fragment $S 07_{1 \div n}$ in $\mathrm{F}_{2}$ population. DAA fragments were amplified from Nippontbare $\left(\mathrm{P}_{1}\right)$, Taichung $65(\mathrm{P})$. and their $\mathrm{F}_{\text {: }}$ progenies. M: size marker, $\phi$ XI74 IONA digested with Ilae III.

segregation ratios $(\mathrm{P}<0.05)$. This very low percentage is in contrast to data obtained from Indica/Japonica rice crosses where $19-70 \%$ of the markers showed segregation distortions (Xu et al., 1997). PCR missing data might be responsible for these distortions as the alleles showing the amplified bands decreased.

To assign RAPI)s to the rice chromosomes, they were located onto the RFLP framework map previously constructed by Tsunematsu ef al. (1996). Of the 64 RAPD markers detected between Taichung 65 and Nipponbare, 26 RAPDs were also polymorphic between Asominori and IR24, the Japonica and Indica varieties used as parents in the construction of the RFLP framework map. Hence, the putative locations of twenty-two RAPDs were readily determined. Two of these markers were probably the same as those previously mapped by Tsunematsu et al. (1993) as these produced always the same size of bands. The locations of the remaining RAPD markers can not be clearly determined or linked to any linkage group. 


\section{RFLP analysis}

RFLP analysis was also done to assign RAPD linkage groups to the rice chromosomes. Eighteen RFLPs were detected between Taichung 65 and Nipponbare, and the polymorphic frequency is shown in Table 1. This frequency which includes the minor RFLP bands with unknown location on the rice chromosome as well as polymorphic data from 15 Japonica varieties including Nipponbare but not Taichung 65 (analyzed by Rice Genome Research Program) is considercd high to some degree. Twelve RFLP markcrs showing major bands were selected for linkage analysis. Codominant alleles were scored at 10 RFLP loci and dominant alleles at two loci. All the RFLP markers clearly segregated into $1: 2: 1$ or $3: 1$ ratios.

Table. 1 Frequency of polymorphic band in Japonica rice.

\begin{tabular}{llccc}
\hline & Varietal pair* & $\begin{array}{c}\text { Number of } \\
\text { primers } 0 \\
\text { probes }\end{array}$ & $\begin{array}{c}\text { polymorphic } \\
\text { barkds }\end{array}$ & $\begin{array}{c}\text { Frequency of } \\
\text { polymorphic } \\
\text { band (1\%) }\end{array}$ \\
\hline \multirow{2}{*}{ RAPD } & $\begin{array}{l}\text { Nipponbare } \\
\text { Taichung 65 }\end{array}$ & 800 & 69 & 8.6 \\
\cline { 2 - 5 } & $\begin{array}{l}\text { Nipponbare } \\
\text { IR24 }\end{array}$ & 300 & 330 & 110.0 \\
\hline RFLP & $\begin{array}{l}\text { Nipponbarc } \\
\text { Taichung 65 }\end{array}$ & 208 & 18 & 8.7 \\
\hline
\end{tabular}

* For comparison, data obtained from the varietal pair of Japonica (Nipponbare) and Indica (IR24) is included.

\section{Levels of polymorphism}

The level of polymorphisms showed by RAPD and RFLP markers per primer or probe was $8.6 \%$ and $8.7 \%$, respectively (Table 1 ). These polymorphic levels were approximately similar with each other. Considered polymorphisms were those showing not only clear RAPD bands but also those which were fainted or close to other bands. Nevertheless, this result was extremely low compared with other results [Indica/Japonica in this study, $110 \%$; two lines of maize, $34 \%$ by Beaumont et al. (1996); two lines of Arabidopsis thaliana, $20 \%$ by Reiter et al. (1992)]. RFLP frequency (8.7\%) was also extremely lower than those of several combinations of Indica/Japonica varieties (about 80\%) (Antonio $e t$ al., 1996). These results were even lower than what we expected indicating that the two parents used in this study were very closely related compared with the other parents used in the previous mapping.

\section{Map construction}

The linkage map generated from the $F_{3}$ population derived from the cross between Taichung 65 and Nipponbare is shown in Fig. 2. The linkage map spans $338 \mathrm{cM}$ and contains 58 RAPD and 9 RFLP markers. The markers were distributed in 13 linkage groups. Except for one linkage group, 12 linkage groups were assigned to 10 rice chromosomes. Six of RAPD and three RFLP markers could not be linked to any groups. 


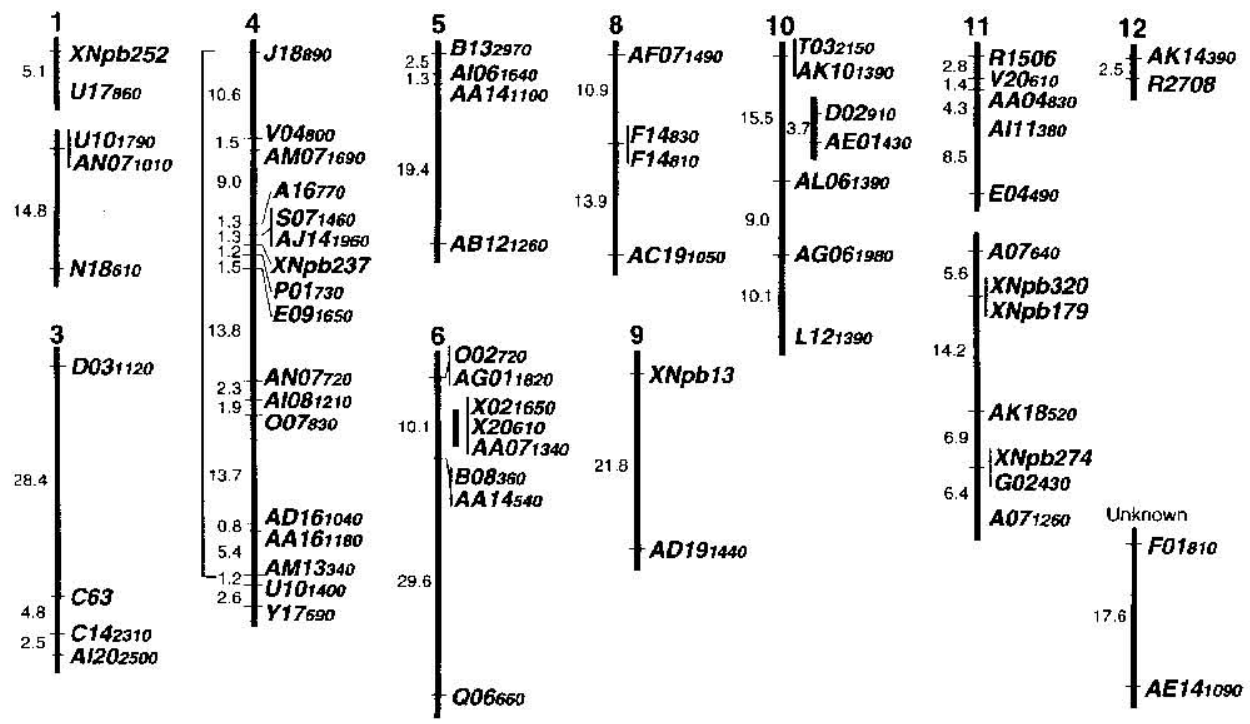

Fig. 2 RAPD-based linkage map in Japonica rice (Taichung $65 \times$ Nipponbare) containung 58 RAPD and 9 RFLP markers. Name of the loci and map distances in $\mathrm{CM}$ are indicated on the right and left of the linkage group, respectively. The RAPD markers are shown with primer names and size of polymorphic fragment. The markers with prefix $X N p b, C$ and $R$ show RFLP makers. Bracket at the left of chromosome 4 indicates that interval distances between loci were determined from the difference with the codominant markers $X N p b 237$. Some markers on chromosomes 6 and 10 were shown separately as their putative orders on the chromosome were difficult to establish.

The order of genes on chromosome 4 were determined mainly from the codominant marker (RFLP marker; XNpb297) and dominant markers in coupling phase. Arrangement of genes on chromosomes 6 and 10, on the other hand, were generally determined based only on the dominant markers in coupling phase. As a result, the definite order of some loci on these chromosomes can not be clearly determined and presented as separate block of genes within the linkage group. As for the other linkage groups, most of the dominant markers are flanked by either codominant or dominant markers in coupling phase.

As most of the markers were detected on chromosome 4, it is possible that the genome structure of Taichung 65 and Nipponbare greatly differ on chromosome 4 . In contrast, chromosomes 2 and 7 must be closely similar as no markers were located on them.

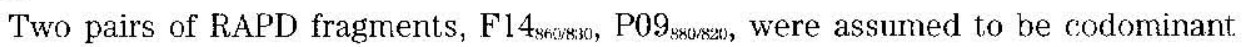
markers since both fragments segregaled into 1:2:1 ratio, showed no null phenotypes and were located on almost the same position on the map. If this assumption is correct, these markers can be more useful for linkage analysis in $\mathbf{F}_{2}$ population than the dominant markers. The homology of the two putative alleles, therefore, needs to be confirmed by Southern hybridization. 
Recently, molecular linkage maps based on the crosses between more closely-related varieties like Japonica/Javanica cultivars (Redona and Mackill, 1995) and Japonica JJaponica (Shimano et al., 1996) have been constructed using RAPDs and RFLP probes obtained by representational difference analysis (RDA) respectively. These molecular linkage maps and the linkage map developed in this study will be useful for the analysis of the important genes in Japonica rice.

When RAPD markers are used for map construction, recombinant inbred (RI) lines or backcross populations are more efficient to use as mapping population than $\mathrm{F}_{3}$ population (Reiter et al., 1992). Construction of Japonica rice linkage map and QTL analysis using RI lines from the $F_{2}$ population in this study are now under way.

\section{REFERENCES}

Antonio, B. A., T. Inone, H. Kajiya, Y. Nagamura, N. Kurata, Y. Minobe, M. Yano, M. Nakagahra and T. Sasaki 1996 Comparison of genetic distance and order of DNA markers in five populations of rice. Genome, 39: 946-956

Allard, R. W. 1956 Formulas and tables to facilitate the calculation of recombination values in heredity. Hilgardia, 24: $235-278$

Beramont, V. H., J. Mantet, T. R. Rocheford and J. M. Widholm 1996 Comparison of RAPL) and RFLP markers for mapping $\mathrm{F}_{2}$ generations in maize (Zea mays L.). Theor. Appl. Genet., 93: 606-612

Causse, M. A., T. M. Fulton, Y. G. Cho, S. N. Ahn, J. Chunwongse, K. Wu, J. Xiao, Z. Yu, P. C. Ronald, S. E. Harrington, G. Second, S. R. McCouch and S. D. Tanksley 1994 Saturated molecular map of the rice genome based on an interspecific backcross population. Genetics, 138: 1251-1274

Kurata, N., Y. Nagamura, K. Yamamoto, Y. Harushima, N. Sue, J. Wu, B. A. Antonio, A. Shomura, T. Shimizu, S-Y. Lin, T. Inoue, A. Fukuda, T. Shimano, Y. Kuboki, T. Toyama, Y. Miyamoto, T. Kirihara, K. Hayasaka, A. Miyao, I. Monna, H. S. Zhong, Y. Tamura, Z-X. Wang, T. Momma, Y. Umehara, M. Yano, T. Sasaki and Y. Minobe 1994 A 300 kilobase interval genetic map of rice including 883 expressed sequences. Nature Genet., $8: 365-372$

MeCouch, S. R., G. Kochert, Z. H. Yu, Z. Y. Wang, G. S. Khush, W. R. Coffman and S. D. Tanksley 1988 Molecular mapping of rice chromosomes. Theor. Appl. Genet., 76: 815-829

Redoña, E. D. and D. J. Mackill 1995 A molecular genetic map of Japonica rice. Rice Genetics Newsletter, 12: 241-244

Reiter, R. S., J. G. K. Williams, K. A. Feldmann, J. A. Rafalski, S. V. Tingey and P. A. Scolnik 1992 Global and local genome mapping in Arabidopsis thaliana by using recombinant inbred lines and random amplified polymorphic DNA.s. Proc. Natl. Acad. Sci. USA, 89: 1477-1481

Rogers, S. O. and A. J. Bendich 1988 Extraction of DNA from plant tissues. Plant Mol. Biol. Manual, A6: $1-10$

Saito, A., M. Yano, N. Kishimoto, M. Nakagahra, A. Yoshimura, K. Saito, S. Kuhara, Y. Ukai, M. Kawase, T. Nagamine, S. Yoshimura, O. Icieta, R. Onsawa, Y. Hayano, N. Iwata and M. Sugiura 1991 Linkage map of restriction fragment length polymorphism loei in rice. Japan. J. Breed., 41: 665-670

Shimano, T., M. Yano, Y. Nagamura and T. Sasaki 1996 Genetic analysis on a population derived from japonica rice varieties. 1. Construction of rice RFLP linkage map using $\mathrm{F}_{2}$ population between Koshihikari and Akihikari. Breed. Sci., 46 (Suppl. 2): 80 (in Japarese)

Tsunematsu, H., H. Hasegawa, S. Yoshimura, A. Yoshimura and N. Iwata 1993 Construction of an RFLP/RAPD linkage map by using recombinant inbred lines. Rice Genetics Newsletter, 8: 139-141

Tsunematsu, H., A. Yoshimura, Y. Harushima, Y. Nagamura, N. Kurata, M. Yano, T. Sasaki and N. Iwata 1996 RFLP framework map using recombinant inbred lines in rice. Breed. Sci, 46: 279-284

Welsh, J. and M. McClelland 1990 Fingerprinting genomes using PCR with arbitrary primers. Nucleic Acids Research, 18: 7213-7218 
Willians, J. G. K., A. R. Kubelik, K. J. Livak, J. A. Rafalski and S. V. Tingey 1990 LNA polymorphisms amplified by arbitrary primers are useful as genetic markers. Nucleic Acids Reseor $h, 18$ : $6531-6535$

X11, Y., L. Zhu, J. Xian, N. Huang and S. R. McCouch 1997 Chromosomal regions associated with segregation distortion of molecular markers in $\mathrm{F}_{2}$, backcross, doubled haploid, and recombinant inbred populations in rice (Oryza sativa L.). Mol. Gen. Gemet, 253: 535-545 